\title{
O EMPODERAMENTO E A EMANCIPAÇÃO DOS SUJEITOS ENQUANTO PRESSUPOSTOS DE EFETIVIDADE DA PARTICIPAÇÃO SOCIAL
}

\author{
EMPOWERMENT AND EMANCIPATION OF SUBJECT AS ASSUMPTIONS OF \\ SOCIAL PARTICIPATION EFFECTIVENESS
}

\author{
${ }^{1}$ José Roniel Morais Oliveira \\ ${ }^{2}$ Ilzver de Matos Oliveira
}

\section{RESUMO}

O presente trabalho visa refletir sobre o aspecto "empoderamento" dos sujeitos como elemento fundamental para a emancipação destes com fulcro na realização e efetividade da participação social. Demonstra-se que embora o Brasil possua considerável abertura normativa acerca do tema, tal imprescinde de uma sociedade mais atuante e imbrincada na construção de uma democracia que seja reflexo do seu povo. Assim, levantado o objetivo e a problemática, por meio de uma pesquisa hipotético-dedutiva e documental foi possível defender que a partir do empoderamento social é possível tanto um aprofundamento da democracia quanto a realização da emancipação social cidadã.

Palavras-chave: Democracia participativa. Empoderamento. Emancipação.

\begin{abstract}
This paper aims to reflect on the aspect of "empowerment" of individuals as a fundamental element for the emancipation of these with fulcrum in the realization and effectiveness of social participation. It shows that although Brazil has considerable normative openness on the subject, such imprescinde a more active society and imbricate in building a democracy that is a reflection of its people. Thus raised the goal and the problem through a hypotheticaldeductive and documentary research it was possible to argue that from the social empowerment is possible both a deepening of democracy and the realization of citizens' social emancipation.
\end{abstract}

Keywords: Participatory democracy; Empowerment; Emancipation.

\footnotetext{
${ }^{1}$ Mestrando em Direitos Humanos da Universidade Tiradentes (UNIT), Aracaju, Sergipe, Brasil. Membro pelo Grupo de Pesquisa Políticas Públicas e Direitos Humanos pela Universidade Tiradentes (UNIT), Aracaju, Sergipe, Brasil. Email: onieloliveira46@gmail.com

${ }^{2}$ Doutor em Direito pela Pontifícia Universidade Católica do Rio de Janeiro (PUC-Rio), Rio de Janeiro, Brasil. Professor Pleno do Mestrado em Direito pela Universidade Tiradentes (UNIT), Aracaju, Sergipe, Brasil. Vice-líder e pesquisador pelo Grupo de Pesquisa Políticas Públicas e Direitos Humanospela Universidade Tiradentes (UNIT), Aracaju, Sergipe, Brasil. Email: ilzver@gmail.com
} 


\section{INTRODUÇÂO}

A Constituição da República Federativa do Brasil de 1988 (CRFB/88), ao normatizar a organização e funcionamento do Estado Brasileiro, bem como suas instituições de operacionalização para organização da sociedade, adotou como regime de governo a Democracia. Tal contexto se deu indubitavelmente logo após um período histórico de ditadura militar, e, portanto, de cerceamento de liberdades fundamentais, notadamente ao direito à livre expressão do pensamento e a exclusão e repressão daqueles que se opunham as ideias defendidas pelo detentor do poder.

Fruto de anseios e lutas das mais diversas categorias da sociedade, em contraposição ao anterior modelo autoritário, veio a $\mathrm{CRFB} / 88 \mathrm{em}$ seu texto formal trazer a ideia de um Estado Democrático onde se tem a pretensão de que o povo, como elemento fundamental e parte integrante do Estado também tem o poder que o exerce diretamente - participando, portanto - ou por meio de representantes.

Neste contexto, parte-se num primeiro momento da premissa de que a realização e a vivência da democracia se devem ao povo, embutido ou não em grupos e/ou classes de movimentos sociais, participando ativamente das decisões que permeiam questões importantes da sociedade. Em um segundo momento, reconhece-se que o modelo de Democracia Representativa não tem se mostrado eficaz na medida em que existe um descompasso entre os anseios da população e as políticas públicas implementadas ou mesmo a omissão estatal de proteção social, especialmente quando os representantes políticos legislam e executam políticas em favor do mercado subjugado pelo capitalismo.

Neste contexto, defende-se que o caminho para uma efetiva democracia onde os cidadãos possam ser ouvidos e sintam-se integrantes, construtores e modificadores de suas realidades, e, portanto, "protagonistas da sua própria história" 3 paira em torno da participação. No entanto, para pensar a Democracia Participativa, faz-se relevante discutir a questão do empoderamento a que discute neste trabalho. É preciso empoderamento dos indivíduos para que eles tenham condições mínimas de participar. Defende-se, assim, que antes mesmo de termos previsão formal de abertura à participação, é preciso termos indivíduos que se sintam empoderados para exercer o referido múnus democrático de modo a torna-los cidadãos sujeitos emancipados e livres de sistemas de dominação e opressão.

\footnotetext{
${ }^{3}$ Expressão muito utilizada por Gohn (2004).
} 
Dada esta problemática, salienta-se que o tema em questão possui uma relevância que está relacionada à ideia de que é preciso que haja um aprofundamento na democracia de modo que esta seja uma instancia de lutas também contra hegemônicas às esferas tradicionais de exercício de poder, e, por conseguinte, necessidade de transformação e desenvolvimento progressista a partir dos próprios sujeitos embutidos e engajados na concretização dos direitos.

Para tanto, utiliza-se de uma metodologia do tipo hipotético-dedutiva, trabalha-se também com documentos como a CRFB/88, No tocante à técnica de pesquisa, será adotada a documentação indireta, tendo como foco a pesquisa documental e bibliográfica. Serão utilizados documentos, principalmente, livros que abordem a temática concernente à participação social e a concretização constitucional, artigos científicos, a própria Constituição Federal, bem como se faz uso de teorias e abordagem de conceitos como o de "Empoderamento" e "participação social".

O presente trabalho está organizado de maneira que na primeira seção há uma defesa da participação social como elemento importante para a concretização da constituição; na seção seguinte trabalha de maneira breve o modo como a participação social está estruturada normativamente, apresenta neste estudo a previsão e o reconhecimento da sua importância tanto na constituição quanto em documentos internacionais; na ultima seção é possível debruçar-se sobre o conceito de "empoderamento" e o modo como tal elemento revela-se importante para a participação social de maneira a atribuir maior legitimidade à democracia e a sua importância também na realização da emancipação social enquanto elemento que se apresenta como fio condutor da realização da dignidade humana ${ }^{4}$.

\section{A CONCRETIZAÇÃo CONSTITUCIONAL POR MEIO DA DEMOCRACIA PARTICIPATIVA}

Antes, uma nota: o estudo que hora aqui se desenvolve desencadeia-se e tem como plano de fundo e objetivo maior contribuir para a concretização constitucional. Nesta ceara defende-se, sobretudo, que a efetividade da carta estruturante do Estado imprescinde de

\footnotetext{
${ }^{4} \mathrm{O}$ sistema normativo Brasileiro considera à dignidade da pessoa humana como sendo o epicentro normativo pelo qual o Estado deve atuar por meio das suas instituições para a plena realização humana em temos de dignidade. Neste trabalho, tem-se uma visão de que tal dignidade para ser efetivada e vivenciada imprescinde de respeito aos sujeitos considerando-os atores sociais importantes na construção da história.
} 
cidadãos participantes e atuantes nos processos decisórios e deliberativos das instituições político-democráticas da república.

Por óbvio, no trato do tema relativo à efetividade constitucional há que se deixar claro um recorte: trabalha-se aqui a constituição a partir da vivência da política ${ }^{5}$, ou, mais especificamente de como o regime democrático pode ser uma instancia que garanta a concretização das promessas constitucionais. É justamente nesta ceara de estudo que se introduzem as reflexões relativas à participação democrática dos cidadãos no processo de efetividade das promessas constitucionais e aprofundamento da democracia.

Há que se discutir que a ideia de Estados constitucionais com suas promessas de liberdade, igualdade, solidariedade e democracia, são ideais típicos da constituição do Estado moderno. Neste contexto, no entanto, discute-se hoje a crise da modernidade, e há quem fale no advento de uma pós-modernidade. Neste contexto, "afirma-se que a modernidade falhou nos seus objetivos, pois não conseguiu resolver ou minimizar os problemas da humanidade, nem dar respostas para as questões verdadeiramente importantes para as pessoas." (SARMENTO, 2004, p. 55-56).

Assim, a ideia de que a regulação e a carta constitucional cheia de promessas, de maneira simbólica, resolveriam os problemas resta ultrapassada. O agir sobre ela e com ela é que a faz um instrumento possível de efetividade dos direitos. Mas não se trata somente do agir hegemônico do Estado por meio de suas funções executivas, legislativas e judiciárias. Trata-se, sobremaneira, também do agir contra-hegemônico das resistências e forças sociais.

Trabalha-se, pois, com a ideia de que para se ter uma constituição efetiva é preciso que as múltiplas forcas da sociedade composta por movimentos sociais e, de todo um modo, de uma sociedade imbrincada e atuante na realização das promessas constitucionais. Essa ideia lembra, de certo modo, o conceito de constituição pautado em Ferdinand Lassalle de que tal é composta pela soma dos fatores reais de poder, sob o qual se atribui poder também a pequena burguesia e classe operária por meio da resistência dessas perante a negação de suas liberdades (LASSALE, 1933).

\footnotetext{
${ }^{5}$ Há que se deixar clara a ciência no crescente esforço de teorias relacionadas a concretização constitucional no âmbito do judiciário, notadamente a fenômenos relativos ao alargamento da jurisdição constitucional por meio de teorias como a atribuição de carga normativa aos princípios e do próprio texto constitucional, haja vista que no decorrer da história a constituição passou de uma carta meramente política para uma carta também jurídica, com densidade normativa e exigível judicialmente.
} 
Tal perspectiva, embora apresente de acordo com Mendes (2015), uma visão unilateral que trata somente do enfoque sociológico e carece de perspectiva normativa ao defender que o conceito de constituição não tem como deixar de ser carregado da ideologia do constitucionalismo, apesar desta crítica, atribui-se aqui neste estudo a sua importância para entender como a participação por meio das forças, sobretudo as advindas de grupos, movimentos sociais e minorias contribuem para a concretização constitucional.

A importância da participação, inclusive no âmbito da jurisdição constitucional para a sua concretização e efetividade intensifica-se, sobretudo quando se admite que "a constituição não é um sistema fechado e onicompreensivo, (...) apenas um conjunto de princípios concretos e elementos básicos (...) para o que oferece uma norma marco. Nesse sentindo, é um ordenamento aberto", Hesse (2009, p. 09). E, como tal, esta abertura abre espaço para que a participação social a complemente de maneira a efetivá-la.

Embora como se tenha demonstrado não ser o objetivo principal desse estudo, não se pode furtar a análise de que o papel do Direito e o avanço e ampliação da jurisdição constitucional tem sido um instrumento importante pelo qual a sociedade tem começado a exigir direitos, de maneira que "o Direito pode ser usado para reativar a esperança coletiva" (BOAVENTURA, 2002, p. 320).

Reconhece-se, ainda, em Ubrimny e Garcia-Villegas (2002, p. 335), que "a justiça constitucional pode chegar a ser importante para o progresso democrático, sempre e quando for entendida como um componente de lutas sociais mais amplas". No entanto, uma advertência: "a luta política por meio do Direito é acusada de obscurecer o verdadeiro rumo da luta política e por essa via 'des-ideologizar' os movimentos sociais e de desagregar os seus membros", Ubrimny; Garcia-Villegas, (2002, p.332). Desta maneira, ainda segundo o autor:

É preciso ter em conta que, embora a produção do Direito com fins de legitimação tenha sido uma estratégia mais ou menos fecunda de dominação social, é também uma arma de dois gumes, na medida em que eventualmente os símbolos da mudança social e proteção dos direitos que ela representa podem ser a vir propriedade dos movimentos sociais, do indivíduo ou até de instituições do Estado, e, de maneira particular, de juízes que levam a sério o direito e utilizam-no como instrumento de resistência e emancipação contra o poder hegemônico. Neste caso, a força interna ou jurídica do Estado pode ser um elemento útil para articular práticas sociais emancipatórias ou no mínimo um instrumento de resistência ao poder hegemônico. UBRIMNY ; GARCIA-VILLEGAS, (2002, p. 304). 
Neste mesmo sentido, Ubrimny e Garcia-Villegas (2002), ainda assevera que o poder emancipatório das decisões no âmbito da jurisdição constitucional está em que elas tem uma certa margem política em que se concretiza a efetividade da esperança depositada no texto constitucional. E, assim, os atores sociais encontram também no espaço de atuação jurídico um ambiente de luta pela concretização da constituição.

Um espaço de luta motivado pela ação política, só que no âmbito do direito, sendo que neste interim os tribunais constitucionais passam a ser importantes para as práticas políticas na medida em que "facilita a consciência política emancipatória de alguns grupos sociais excluídos (...) na medida em que criam, ajudam a criar ou fortalecem a identidade do sujeito político" Ubrimny e Garcia-Villegas, (2002, p. 322).

Para finalizar, atem-se ao atributo de que Direito e política, embora sejam instâncias autônomas e cada um desses espaços tenham funções específicas, considera-se que ambas as cearas estão submetidas na realização da constituição como fim ultimo de atuação. No entanto, muito embora tenha acontecido certa transferência de lutas sociais para o campo do Direito, considera-se que a luta política no âmbito das outras esferas de poder sejam intensificada, e, neste fito democrático, mais uma vez alude-se a importância do empoderamento social.

\section{O DIREIO A PARTICIPAÇÃO SOCIAL INSTITUCIONALIZADO}

Quando o tema em questão é relacionado à participação, sobretudo sua relação com a democracia, pode-se elencar inicialmente três momentos que estão correlacionados para sua efetividade na prática, ou três vieses principais de estudo:

Em um primeiro momento, pode-se trabalhar com a ideia de participação analisandose os instrumentos que o impulsionam à sua realização, ou seja, nesse instante as análises e os estudos serão para responder a questões como: quais são os instrumentos de participação democrática? Eles estão concentrados em todas as esferas das funções estatais ${ }^{6}$ (legislativo, executivo e judiciário), bem como em todos os níveis de governo (Federal, Estadual, Distrital e municipal?)? O objetivo principal deste estudo, no entanto, embora não se concentre neste primeiro olhar sobre o tema atinente à participação, tal revela-se importante na medida em

\footnotetext{
${ }^{6}$ Preferiu-se utilizar do termo "funções estatais" em substituição ao termo "poderes estatais" justamente por considerar o primeiro melhor empregado em um Estado Democrático de Direito em que de acordo com a constituição o poder é do povo.
} 
que ter instrumentos participativos é à base de quaisquer outros estudos acerca de como esses elementos estão funcionando ou se tais instrumentos estão sendo efetivos na construção de um regime democrático forte.

Não obstante, alude-se que "o sistema político gerado pela Constituição de 1988 é um sistema híbrido que incorporou na sua organização amplas formas de participação no plano do processo decisório federal, assim como, no plano local.” Avritzer (2006, p. 35). Tem-se, portanto, que ainda que duas tenham sido as principais formas que a constituição de 1988 trouxe de participação, a primeira por meio de instrumentos como plebiscito, referendo e iniciativa popular ${ }^{7}$, destacando-se ai formas diretas de participação, a segunda ligada ao controle e construção de políticas sociais, sendo essas ultimas objeto de iniciativas no plano mais local e destaca-se em temas como a seguridade social e reforma urbana. (AVRITZER, 2006).

Embora se reconheça que o Brasil tenha avançado em termos de legislação normativoconstitucional de garantia formal à participação democrática conforme estudo de Oliveira e Marques (2015), em que faz menção a diversos dispositivos constitucionais garantidores de participação. Seguindo, ainda, literalmente que "são diversas as passagens da Constituição Federal de 1988 que tratam das normas de institutos participativos na Administração Pública" Oliveira e Marques (2015, p. 103).

É possível também vislumbrar que a constituição de 1988 alargou as possibilidades de participação nas demais esferas de poder para além do federal. De acordo que Estados e Municípios possuem também esta previsão normativa ${ }^{8}$. E, de igual modo, como já foi dito, trouxe sua previsão também para as outras funções da república, para além do executivo, de maneira que há dispositivos que garantem a participação no âmbito do legislativo9 .

Neste sentido, a partir da constituição de 1988 o Brasil passou a integrar "um grupo bastante seleto de países que não têm na representação o monopólio das formas de expressão

\footnotetext{
${ }^{7}$ Tais instrumentos encontram-se no artigo 14, incisos I, II e III da Constituição da República Federativa do Brasil de 1988 que dispõe que a "soberania popular será exercida pelo sufrágio universal e pelo voto direto e secreto, com valor igual para todos, e, nos termos da lei, mediante: plebiscito; referendo, iniciativa popular". (BRASIL, 1988)

${ }^{8}$ Como se encontra no artigo 27 da Constituição de 1988 que dispõe que "lei disporá sobre a iniciativa popular no processo legislativo estadual". E artigo 29, incisos XII e XIII que dispõe "Município reger-se-á por lei orgânica, (...) atendidos os princípios estabelecidos nesta Constituição, na Constituição do respectivo Estado e os seguintes preceitos: (...) iniciativa popular de projetos de lei de interesse específico do município, da cidade ou de bairros, através de manifestação de, pelo menos, cinco por cento do eleitorado...”. (BRASIL, 1988)

${ }^{9}$ Conforme dispõe o artigo 61 da constituição de 1988: "iniciativa popular pode ser exercida pela apresentação à Câmara dos Deputados de projeto de lei subscrito por, no mínimo, um por cento do eleitorado nacional distribuído pelo menos por cinco estados, com não menos de três décimos por cento dos eleitores de cada um deles" (BRASIL, 1988).
} 
política institucionalizadas" Avritzer (2006, p. 35). Bem como lembra o estudioso que do ponto de vista da arquitetura constitucional são poucos os países que possuem na constituição a combinação entre representação e participação no modelo de estrutura constitucional. (AVRITZER, 2006).

De todo modo, em um segundo momento, vislumbra-se que as reflexões acerca da participação em um Estado Democrático de Direito pode caminhar também por estudos que sejam inerentes em responder se os instrumentos que estão postos à participação democrática são efetivos no sentido de que aquilo que as organizações participativas conseguem deliberar por meio dos instrumentos participativos nas instituições estatais são efetivamente postos em prática no agir do Estado.

Tal agir estatal revela-se por meio das suas políticas públicas, no caso do Executivo; são levadas em consideração no agir legislativo em suas atividades legiferantes; e são levados em consideração na fundamentação das decisões judiciais, destarte que embora juízes possam decidir de acordo com seu livre convencimento, tal precisa ser fundamentado, e, nesta ceara alude-se a importância das audiências públicas no âmbito dos tribunais para que também os espaços jurídicos sejam espaços de aplicação justa do direito, destarte a jurisdição ser um dos espaços de efetividade e construção do Estado Democrático.

O desenrolar de pesquisas nesse campo da efetividade dos instrumentos participativos é extremamente importante uma vez que, embora haja formalmente no texto constitucional que o poder emana do povo que o exerce também de maneira $\operatorname{direta}^{10}$, e, para isso haja os instrumentos de participação, estes precisam ser efetivos e vivenciados na prática para que a cidadania seja efetivamente plena.

$\mathrm{O}$ direito à participação social revela-se como instrumento indissociável à ideia de cidadania $^{11}$, que foram legitimamente positivados na constituição e em leis infraconstitucionais, bem como a previsão em documentos internacionais acerca da previsão da participação social como mecanismo importante para as democracias, a exemplo da Declaração sobre o Direito ao Desenvolvimento de 1986 no âmbito da Organização das

\footnotetext{
${ }^{10}$ Nos termos do Artigo $1^{\circ}$, parágrafo único, da constituição de 1988: "Todo o poder emana do povo, que o exerce por meio de representantes eleitos ou diretamente, nos termos desta Constituição". (BRASIL, 1988).

${ }^{11}$ Conforme artigo $1^{\circ}$, inciso II, da Constituição de 1988, a cidadania é um dos fundamentos da Republica Federativa do Brasil. (BRASIL, 1988)
} 
Nações Unidas $(\mathrm{ONU})^{12}$, a Declaração Universal dos Direitos Humanos ${ }^{13}$ e o Pacto Internacional dos Direitos Civis e Políticos ${ }^{14}$.

Percebe-se, pois, que as formas de se exercer a soberania popular por meio de uma participação da população nas questões relacionadas as decisões importantes para o país "estão amplamente incorporadas no texto constitucional ainda que elas tenham sido pouco exercidas no Brasil democrático" (AVRITZER, 2006, p. 36).

É justamente neste ponto que situa o desenrolar da presente pesquisa. Há uma lacuna existente entre de um lado uma constituição que confere poderes aos seus cidadãos, bem como existem documentos internacionais com previsões no mesmo sentido. Vislumbra-se que há, portanto, de maneira formal textos normativos garantidores do exercício democrático da participação como fora demonstrado neste capítulo. Há, também, o desenvolvimento de teorias reconhecendo a participação democrática como elemento importante para a concretização constitucional, controle social e efetividade de políticas públicas como foram discutido no primeiro capítulo desta pesquisa.

De outro lado, porém, nota-se que embora haja instrumentos garantidores de liberdades à participação pelo menos no âmbito formal, e o desenvolvimento de teorias reconhecendo tal elemento importante ao desenvolvimento do Estado, não há no seio da sociedade uma cultura amplamente democrática de participação ou tais cidadãos não se sentem empoderados, detentores de poder transformador, modificador e significador das realidades sócio-políticas.

Sentem-se, nestas perspectivas, frágeis diante de instancias hegemônicas estatais de resolver os negócios do Estado somente por meio dos representantes eleitos. Destarte que não se trata de negar o Estado e as instituições democráticas, trata-se tão somente de alargar as dimensões do exercício da cidadania participativa de modo a atribuir maior densidade à democracia enquanto sistema cujo povo é fulcral para a sua plena realização.

\footnotetext{
12 Adotada pela Revolução n. ${ }^{\circ}$ 41/128 da Assembleia Geral das Nações Unidas, de 04 de dezembro de 1986. Onde em seu artigo $2^{\circ}$, parágrafo $1^{\circ}$ dispõe que "a pessoa humana é o sujeito central do desenvolvimento e deveria ser participante ativo e beneficiário do direito ao desenvolvimento".

${ }^{13}$ Que em seu artigo XXI, 1. Dispõe que "todo ser humano tem o direito de fazer parte no governo de seu país diretamente ou por intermédio de representantes livremente escolhidos".

${ }^{14}$ Onde assegura em seu artigo 25 que "todo cidadão terá o direito e a possibilidade sem qualquer das formas de discriminação mencionadas no artigo $2^{\circ}$ e sem restrições infundadas: a) de participar da condução dos assuntos públicos, diretamente ou por meio de representantes livremente escolhidos".
} 


\section{PARTICIPAÇÃO DEMOCRÁTICA SOB O VIÉS DO EMPODERAMENTO E DA EMANCIPAÇÃO SOCIAL}

Como já mencionado neste trabalho, atribui-se ao aspecto do empoderamento uma ferramenta necessária para que atores sociais engajem-se na participação democrática e controle social. Formalmente, no texto constitucional diz-se que o poder é do povo que pode exercê-lo diretamente, no entanto vislumbra-se que este - o povo - precisa estar empoderado de modo a conceber este elemento como condição mínima à participação democrática.

Neste fito, imprescindível trabalhar com o conceito de empoderamento, segundo o qual Gohn analisa que "o significado da categoria "empowerment" ou empoderamento como tem sido traduzida no Brasil, não tem um caráter universal.” Gohn (2004, p. 22). De modo que, segundo a autora, o empoderamento poderá estar referindo-se ao "processo de mobilizações e práticas destinadas a promover e impulsionar grupos e comunidades - no sentido de seu crescimento, autonomia, melhora gradual e progressiva de suas vidas" Gohn (2004, p. 22). Quanto pode também referir-se a ações destinadas a "promover simplesmente a pura integração dos excluídos, carentes e demandatários de bens elementares à sobrevivência, serviços públicos, atenção pessoal, etc" GOHN (2004, p.22).

Segundo a autora Gohn (2004), dois outros conceitos são importantes para entender melhor o aspecto do empoderamento nas sociedades democráticas, são eles o conceito de comunidade cívica, segundo o qual se materializa no momento em que se tem cidadãos e comunidade imbuídos de espírito público, de maneira que as relações sejam igualitárias e, ainda, pautadas na colaboração e confiança. E, aliado a este, o conceito de capital social, ao qual a autora se reporta à teoria de Robert Putman fazendo-se contraposição ao individualismo que ainda é impregnado nas comunidades, de modo que neste contexto, capital social "refere-se à conexão entre indivíduos, redes sociais e as normas de reciprocidade e lealdade que nascem deles" Gohn (2004, p. 24).

Debruçando-se sobre os estudos acerca do empoderamento, os autores Peter Oakley e Andrew Clayton (2003), elencam que o aspecto "poder" exerce um papel importante na determinação dos que progridem e dos que não progridem em uma dada realidade ou comunidade, sobretudo quando está relacionado a estruturas administrativas que regulam a vida das pessoas e as oportunidades de avanço por meio de acesso a recursos. OAKKEY; CLAYTON (2003, p. 08).

Trabalhar o aspecto do empoderamento em uma sociedade democrática participativa, nesse sentido, é importante, sobretudo quando se verifica que uma das vertentes do 
desenvolvimento sustentável ${ }^{15}$ é a questão social, a vivência da dignidade em termos de condições de vida a propiciar o desenvolvimento dos múltiplos sujeitos dotados de suas individualidades e pluralidades na construção do espaço em que se vive. Somente, pois, o povo embutido em suas realidades locais ${ }^{16}$ e no seio das suas culturas, bem como o respeito, reconhecimento e exaltação a essas identidades de modo a fazer delas, fontes de legitimidade para a transformação progressista é que se considera o início de um efetivo empoderamento ${ }^{17}$ para vias de emancipação social. De acordo com a conotação deste viés, as ações nesse sentido visam garantir a "capacidade de gerar processos de desenvolvimentoauto-sustentável, com mediação de agentes externos - os novos educadores sociais - atores fundamentais na organização de projetos" GOHN (2004, p. 23).

Alinhando-se ao objetivo principal deste trabalho, qual seja demonstrar que o empoderamento das comunidades e dos indivíduos revela-se tarefa fundamental para a emancipação destes com fulcro na realização e efetivação de uma política participativa, aludese que numa perspectiva emancipatória, "empoderar é um processo pelo qual indivíduos, organizações e comunidades angariam recursos que lhes permitam ter voz, visibilidade, influencia e capacidade de ação e decisão”. HOROCHOVSKI; MEIRELLES (2007, p. 486).

Sob o viés do discurso do empoderamento e da emancipação humana e social como condição intrínseca para que haja uma sociedade participativa é que se funda os objetivos trabalho. Como já visto, parte-se, portanto, do pressuposto de que não há efetiva participação quando da existência de uma sociedade distante das questões políticas e sociais, e, mais ainda, a participação não se concretiza também como instrumento modificador de determinada questão social quando o indivíduo que dela se vale não tem sua voz ouvida pelas instituições.

Assim, alude-se a hipótese de que muito embora tenhamos instrumentos de participação social no âmbito inclusive dos três poderes ou funções do Estado, quais sejam o executivo, o legislativo e também do judiciário, percebe-se um certo distanciamento da

\footnotetext{
${ }^{15}$ Trabalha-se aqui com o conceito de desenvolvimento sustentável pautado nos processos de ampliação das liberdades e das possibilidades em se viver uma vida digna em plenitude não somente econômica e ambiental, mas também social moral e cultural. Trata-se, pois, de considerar o ser humano no centro dos processos de desenvolvimento tornando-o ator promotor de mudanças significação e ressignificação de realidades.

${ }^{16}$ Daí a importância já materializada na Constituição de 1988 de maior autonomia a municípios. Embora esta descentralização do poder esteja ainda muito no viés administrativo do Estado, considera-se um avanço importante, mas pequeno diante de possibilidades de empoderamento da comunidade, sobretudo da comunidade organizada em movimentos de lutas sociais.

${ }^{17}$ O termo "empoderamento" com a conotação política emancipatória foi ouvido pela primeira vez no início dos anos 1970, mesmo ainda no original inglês empowerment, e os principais emissores foram movimentos feministas e negros. Tem-se, portanto que desde a sua raiz, o termo guarda intrínseca relação com grupos e movimentos sociais em busca de justiça social, libertação de situações de opressão e dominação com o fito principal de emancipação.
} 
população por questões políticas, e, muito embora tenhamos visto nos últimos anos o florescimento de mobilizações sociais, estas não se concretizam em espaços de comunicação e troca de saberes e experiências de maneira que as vozes da rua chegue efetivamente às instituições e estas tornem-se transformadoras ou contribuam para os processos decisórios.

A participação pode ser entendida como conquista através das lutas de resistências da sociedade contra toda forma de opressão e exclusão, como processo contínuo de autopromoção humana, jamais entendida simples e unicamente como concessão, haja vista constituir a base fundamental do Estado. De acordo com Demo (1998) a participação aparece como processo que tem por objetivos a autopromoção como forma de superação da situação assistencialista, a realização da cidadania, o exercício democrático por meio do qual se participa e vivencia a construção e transformação política e social da sociedade, bem como, a participação objetiva o controle do poder e da burocracia pelo povo, a implementação da negociação como forma de solução de conflitos e a consolidação de uma cultura democrática (DEMO, 1988, p. 66-79).

Reconhece-se em Rúbio (2014) a capacidade de toda pessoa significar e ressignificar realidades, essa é inclusive a ideia de emancipação humana como uma das faces encantadoras dos Direitos Humanos, ou seja, a participação é um elemento fundamental para a vivencia e efetivação de direitos humanos na medida em que tais direitos são uma instância de luta libertadora por uma dignidade que emancipa. No entanto, de outro modo, entender Direitos somente como conjunto de leis e documentos internacionais, bem como atribuir somente as instituições estatais a sua guarda, pode revelar uma face de dominação, exclusão e inferiorização humanas.

Também Boaventura de Sousa Santos (2007), contribui substancialmente com a ideia de emancipação social e empoderamento trabalhando com a reinvenção da emancipação social principalmente em realidade de países periféricos. O autor, em sua obra "Reinventar a teoria Crítica e Reinventar a Emancipação Social” (2007), ao reconhecer a necessidade de emancipação elenca alguns paradigmas sob os quais será preciso ultrapassar. São eles: a superação da monocultura do saber científico, do tempo linear, da naturalização das diferenças, da escola dominante, da produtividade mercantil do trabalho e da natureza. Para tal superação propõe a valorização de saberes e organizações populares com a ideia de ecologia dos saberes, ecologia das temporalidades, ecologia do reconhecimento, ecologia da transescala e a ecologia das produtividades. BOAVENTURA (2007). 
Dussel (1995) escreve acerca da filosofia da libertação, guardando intrínseca relação com as ideias de emancipação social e direito a participação no sentido de que o outro precisa ser ouvido e essa é condição indissociável de sua libertação de dominação, segundo o qual "não existe libertação sem racionalidade; mas, também, não existe racionalidade crítica sem que se acolha a interpelação do excluído, pois, do contrário, ela seria, embora inadvertidamente, apenas uma racionalidade de dominação" (DUSSEL, 1995, p. 78).

\section{CONSIDERAÇÕES FINAIS}

A principal consideração a que se faz na finalização deste trabalho guarda intrínseca relação com seu objetivo primeiro, qual seja refletir sobre o aspecto "empoderamento" dos sujeitos como elemento fundamental para a emancipação destes com fulcro na realização e efetivação da participação social. Assim, considera-se que uma efetiva participação e controle social se darão a partir do momento em que os sujeitos cidadãos sintam-se não somente parte integrante de maneira passiva considerando-os meros receptores, mas atores sociais construtores e significadores dotados de fonte legítima e primeira de poder na atuação acerca das decisões relativas ao Estado Democrático de Direito.

É possível constatar que empoderar os sujeitos, de modo que estes se sintam atores e parte integrante da comunidade revela-se importante por dois principais motivos: primeiro, quando se considera que a partir de um maior engajamento da sociedade nos espaços públicos há um aprofundamento e uma vivência mais intensa da democracia, este resultado é particularmente importante, sobretudo na medida em que se vê um constante afastamento dos sujeitos do mundo da política, entendida esta como espaço da práxis transformadora; segundo, devido ao aspecto da emancipação social, na medida em que sujeitos participantes, atuantes e proativos fazem do uso da liberdade vias possíveis de externar suas subjetividades, e estas tornam-se contributo à construção social de um Estado que seja reflexo dos seus integrantes.

Importante também salientar que as ideias presentes neste trabalho não se tratam de negar o Estado e as instituições, trata-se tão somente do reconhecimento de categorias como o empoderamento com vias a alargar as dimensões do exercício da cidadania participativa de modo a atribuir maior densidade à democracia enquanto sistema cujo povo é fulcral para a sua plena realização. 
Neste contexto, defendeu-se que o caminho para uma efetiva democracia onde os cidadãos possam ser ouvidos e sintam-se integrantes, construtores e modificadores de suas realidades, e, portanto, protagonistas da sua própria história, paira em torno da participação. Pensar a Democracia Participativa, neste sentido, faz-se relevante, sobretudo a partir do reconhecimento do empoderamento como condição mínima à efetiva cultura participativa cidadã e cívica.

É preciso empoderamento dos indivíduos para que eles tenham condições mínimas de participar. Defende-se, assim, que antes mesmo de termos previsão formal de abertura à participação, é preciso termos indivíduos que se sintam empoderados para exercer o referido múnus democrático de modo a torna-los cidadãos sujeitos emancipados e livres de sistemas de dominação e opressão. Este estudo, pois, contribuiu neste sentido.

Considera-se que a presente pesquisa contribuiu para o estudo concernente à participação social, sobretudo analisando-se o viés de sua realização. Trabalhou-se a sua importância no processo de concretização constitucional, demonstrou-se o reconhecimento de sua relevância por meio de previsão normativa, e ao fim trouxe os elementos do empoderamento como contributos a uma efetiva realização da participação democrática e consequente emancipação social. Infere-se, a guisa de conclusão, na importância do reconhecimento de que novas pesquisas precisam ser feitas para responder a maneira ou de como deve se dar este empoderamento e como ele deve ser implementado.

\section{REFERÊNCIAS BIBLIOGRÁFICAS}

AVRITZER, Leonardo. Reforma política e participação no Brasil. In. Reforma política no Brasil / Leonardo Avritzer, Fátima Anastasia (org.). - Belo Horizonte: Editora UFMG, 2006.

BRASIL. Constituição (1988). Constituição da República Federativa do Brasil. Brasília, DF: Senado Federal: Centro Gráfico, 1988.

DECLARAÇÃO UNIVERSAL DOS DIREITOS HUMANOS. Adotada e proclamada pela resolução 217 A (III) da Assembléia Geral das Nações Unidas em 10 de dezembro de 1948. Disponível na Biblioteca Virtual de Direitos Humanos da Universidade de São Paulo: www.direitoshumanos.usp.br

DEMO, Pedro. Participação é conquista: noções de política social participativa. São Paulo: Cortez, 1988 
DUSSEL, Henrique. Filosofia da Libertação: crítica à ideologia da exclusão. Tradução Georges I. Maissiat. - São Paulo: Paulus, 1995.

GOHN, Maria da Glória. Empoderamento e participação da comunidade em políticas sociais. Revista Saúde e Sociedade. V. 13, p.20-31, 2004

HESSE, Konrad. Temas fundamentais do direito constitucional. Tradução de carlos dos Anjos Almeida. Et al., São Paulo: Saraiva, 2009

HOROCHOVSKI, Rodrigo Rossi; MEIRELLES, Giselle. Problematizando o conceito de empoderamento. In. Anais do II Seminário Nacional Movimentos Sociais participação e Democracia. UFSC, Florianópolis, 2007.

LASSALLE, Ferdinand. O que é uma Constituição? Edições e publicações Brasil. Tradução Walter Stonner. São Paulo, 1933

MARQUES, Verônica Teixeira; OLIVEIRA, Ilzver de Matos. A política nacional de participação social brasileira: uma discussão sobre a promoção estatal da participação através de instrumentos constitucionais e legais. In. I Encontro de Internacionalização do CONPEDI / organizadores: José Fernando Vidal de Souza, Riva Sobrado de Freitas. Barcelona : Ediciones Laborum, 2015. V. 2

MENDES, Gilmar Ferreira. BRANCO, Paulo Gustavo Gonet. Curso de Direito Constitucional. $10^{\mathrm{a}}$ ed. São Paulo. Saraiva, 2015.

OAKLEY, Peter; CLAYTON, Andrew. Monitoramento e avaliação do empoderamento (“empowerment"). Tradução de Zuleika Arashiro e Ricardo Dias Sameshima. São Paulo, Instituto Pólis, 2003.

RUBIO, David Sánchez. Encantos e Desencantos dos Direitos Humanos: de emancipações, libertações e dominações. Tradução Ivone Fernandes Morcilho Lixa, Helena Henkin. Porto Alegre: Livraria do Advogado Editora, 2014.

SANTOS, Boaventura de Sousa. Renovas a Teoria Crítica e Renovar a Emancipação Social. Tradução Mouzar Benedito. São Paulo: Boitempo 2007.

SARMENTO, Daniel. Direitos Fundamentais e Relações Privadas. Rio de Janeiro: Lumen Juris, 2004. 